\title{
Development of an automatic can crusher using programmable logic controller
}

\author{
N. A. A. Hadi' ${ }^{1}$ Lim Hui Yee' ${ }^{2}$ K. A. M. Annuar ${ }^{3}$, Zulhilmi Bin Zaid ${ }^{4}$, Z.A Ghani ${ }^{5}$, \\ M.F. Mohd Ab Halim6 Amar Faiz Zainal Abidin ${ }^{7}$, M.B.N. Shah ${ }^{8}$ \\ ${ }^{1,2,7}$ Centre for Telecommunication Research \& Innovation (CeTRI), Fakulti Teknologi Kejuruteraan Elektrik \& \\ Elektronik (FTKEE), Universiti Teknikal Malaysia Melaka (UTeM), Malaysia \\ ${ }^{3,4,5,6,8}$ Centre for Robotics and Industrial Automation (CeRIA), Fakulti Teknologi Kejuruteraan Elektrik \& \\ Elektronik (FTKEE), Universiti Teknikal Malaysia Melaka (UTeM), Malaysia
}

\begin{tabular}{l} 
Article Info \\
\hline Article history: \\
Received Aug 11, 2018 \\
Revised Nov 20, 2018 \\
Accepted Dec 11, 2018 \\
\hline
\end{tabular}

Keywords:

Automation

Can crusher

HMI

PLC

Pneumatic

\begin{abstract}
The invention of a can crusher machine in this project is to reduce the wasted storage space occupied by the tremendous amount of use aluminium can at the commercial establishment like in the restaurant, cafeteria and bar. Basically, can crusher machine be operated in manual effort and time in the can crushing process. Shrinking the initial volume of empty used-aluminium cans down to $50 \%$ in more effective, faster and effortless way, as well as to develop a low-cost device that is suitable for the small-industry usage are mainly the objectives for the Automatic Can Crusher, where an automated process is executed in Automatic Can Crusher due to the automation in the modern world is inevitable and nominal to be used. The Automatic Can Crusher is run by a Programmable Logic Controller (PLC) with the aid of an inductive and capacitive sensor, where it is applied to detect whether the object is metal or non-metal. Overall, the system can be controlled manually through the push start and stop button as well as using the Human Machine Interface (HMI) using NB-Designer, for displaying the total of cans being crushed per day. The average result of empty can could shrink from $31 \%$ to $60 \%$ of the original value, by using the attuned and compatible pressure for this system.
\end{abstract}

Copyright (c) 2019 Institute of Advanced Engineering and Science. All rights reserved.

\section{Corresponding Author:}

N. A. A. Hadi,

Department of Electronics \& Computer Engineering Technology,

Fakulti Teknologi Kejuruteraan Elektrik \& Elektronik,

Universiti Teknikal Malaysia Melaka,

Hang Tuah Jaya, 76100 Durian Tunggal, Melaka, Malaysia.

Email: nikazran@utem.edu.my

\section{INTRODUCTION}

Nowadays, beverage such as carbonated soft drinks, alcoholic beverages, juices and energy drinks are made up of aluminium and it is proven that $75 \%$ of worldwide production of beverage comes in aluminium. Thus, it is necessary to recycle aluminium as recycling is significant in today's world, in order to preserve our limited natural resources and help in preserving the environment. In addition, recycling not only can help to keep the landfills clear, but it can also help to save energy. In producing a new aluminium beverage can by using a recycled aluminium, it uses $95 \%$ less energy and the greenhouse gases emission is reduced to $95 \%$ compared with making a new can from new materials.

Recycling plays an important role to save our limited natural resources. In 1972, approximately 26,500 tons of aluminium cans were recycled and today that number is estimated to be as high as 800,000 tons. Aluminium is one of the easiest and important material that must be recycled due to people need to deal 
with the tremendous amount of empty leftover beverage. Therefore, various research was carried out to fabricate the can crusher machine and improve the can crusher available in recent years.

A recent study made by [1] concluded that it has a research on the working principle of the can crusher in a pneumatic system using a microcontroller as the backbone of the project. The aim of this research paper is to reduce the scrap volume of the cans so that more wastes can be recycled. According to the research, the minimum operating pressure in bar to crush the can is 3 bar with the condition that the pressure in bar to storage tank must reach 5 bar pressure to turn $\mathrm{ON}$ the compressor. There is a combination of electronics circuit as $5 / 2$ solenoid valve is used to run the cylinder compressor. When there is a can placed in the front of the optosensor, 5/2 directional control valve will operate [2]. In addition to it, it also added and proposed that in order to fulfill the environment protection requirement in designing a can crusher, a pneumatic system is normally composed in the can crusher by driving the pneumatic cylinder to move forward or reversed backward. To make it short, an automatic can crusher machine can simply reduce the volume of the can as well as to reduce the human fatigue. By applying the microcontroller and sensor instead of manual operated tend to give a better result and able to run in the long term as in the future.

Programmable Logic Controller (PLC) is an industrial computer that receives inputs from input devices and interprets the inputs and generates output to control peripheral output devices. The input devices which are either analogue or digital are received from sensors or a machine in the form of voltage and current. Programmable Logic Controller (PLC) is a controller that able to interpret and convert the stimulus to the CPU thereby a set of instructions for the actuators to operate according to the output sequence can be executed accurately in the industrial environment [3].

Pneumatic system is classified under "Fluid Power Control" as it transmits the power through pressurized gas or liquid. Control valves are used to control the flow direction, pressure and flow rate of the compressed air so that it can work well with the actuator for the power control application [4]. The main reason for the extensively used of pneumatic system in fluid power control application especially in sequential and repetitive operations is that the simplicity, economical and it provide an outstanding advantage in terms of safety in the pneumatic system [5].

This paper discusses about design and fabricate of a can crusher machine that operates automatically with the aids of the sensor by using a PLC controller to control the sequence of the can crusher. The aluminum can thereby reduce $70 \%$ of its initial volume so that it can overcome the storage problem people face for the recycling purpose. It starts with the crushing process and the rejection process where both sensors are put in the operation of this part as in the selection of aluminum can or plastic.

\section{SYSTEM CONSIDERATION}

The core of the automatic can crusher machine consists of the combination of the software and hardware using a PLC. Figure 1 shows the block diagram for the automatic can crusher machine. This block diagram shows the PLC controller will be getting the input from the sensors to initiate the correct conditions to control the output sequence of the pneumatic cylinder for the specific actuation by supplying pressure to the electro-pneumatic valve for the cylinder to function. The sensor at the bottom of the hopper will sense the object drop into the crusher machine whether to reject the object or crush the beverage can using the ladder programming in the PLC [6]. In addition, the PLC can also interface with Human Machine Interface (HMI) where HMI provides a touch screen that enables the user to monitor and control the operation of the machine as it provides push button as well as the light indication on the touch screen to control the process flow and monitor the sequence of the can crusher whether it is in operational mode or stop mode. This also can be controlled by the buttons on the hardware. Besides, it also provides a readout graphical displayed to display the number of cans crushed by the crusher machine. The machine also can minus the number of crushed can manually if there is a fail case that the user wants to reject. The whole process of the can crusher machine is simply explained through the flow chart in Figure 2. 


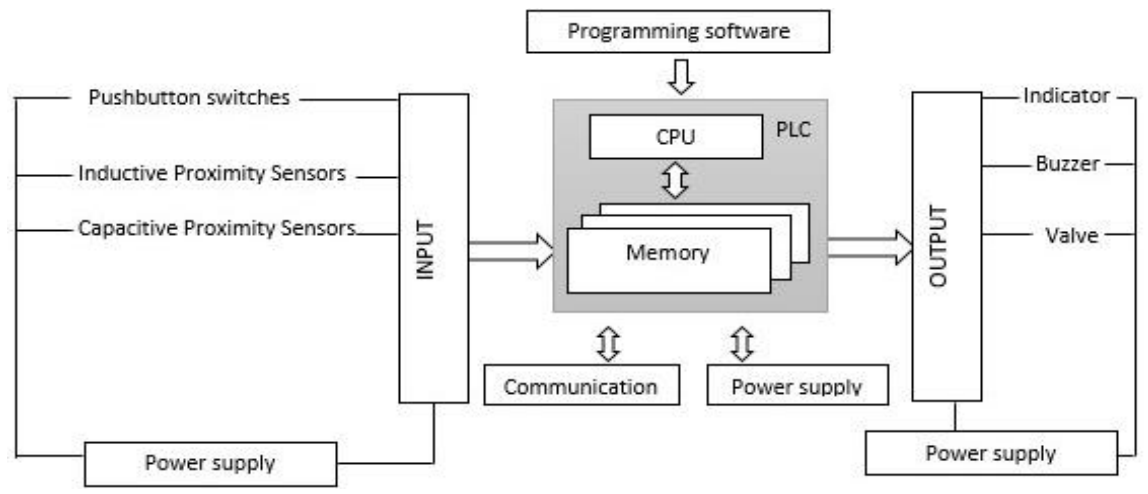

Figure 1. Block diagram of automatic can crusher machin

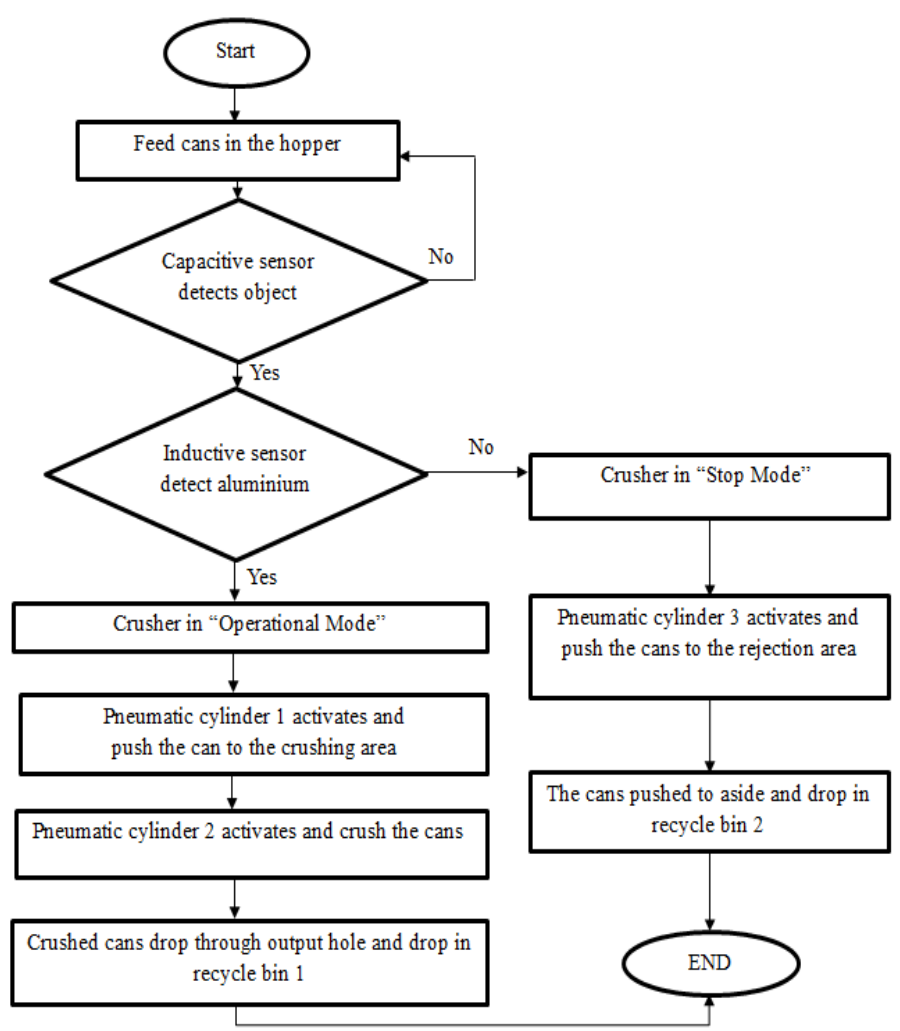

Figure 2. The operation of the automatic can crusher

\section{HARDWARE IMPLEMENTATION}

Figure 3 shows the diagram of the system. The Cylinder A, B and C are the output of the program, in which it is controlled by the single solenoid valve with spring return. Meaning to say that, the valves are the output of the system. All the valves are bringing connected to the output of the PLC. The output is being set for the $24 \mathrm{~V}$. By this, one wire of the valve should be connected to the output, while another is connected to the ground. This applies the same for each component that connected to the output. Meanwhile, for the input, it works another way. The input is being set on the ground. Thus, the connection that connected to the input should be ground and another would be on $24 \mathrm{~V}$. It consists of a roller switch to detect the cylinder whether it is fully retracted or not. The extend part could not be placed in due to the design of the mechanism is not suitable where the hopper space must be precise enough for crushing purpose. 


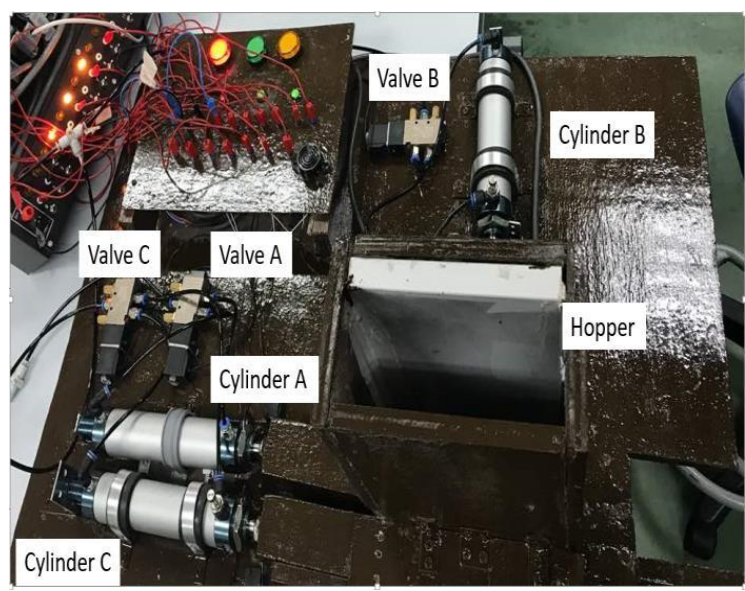

Figure 3. The connection between the cylinder, valve, roller and PLC that involves the automatic can crusher to complete its task

The hardware connection was the first test with the functionality of the cylinders and valves. After testing it, next would be on the sensors which include the inductive and capacitive sensor. The whole prototype is formed based on the placing as in above Figure 3. The can is tested to drop into the hopper where the sensor located at the bottom of it. The mechanism is being designed based on the requirement. If the object is a non-metal, the cylinder A will push the can into the rejection area. Meanwhile, if the can is metal, cylinder B will push to the crushing area and cylinder $\mathrm{C}$ will crush the can. There is a hole located in the crushing area where the can able to drop to the recycle bin.

\section{SOFTWARE IMPLEMENTATION}

The software used in this project is a Programmable Logic Controller (PLC) and Human Machine Interface (HMI). The CX programmer uses a ladder diagram as a software to control the sequence of the whole process. The CX programmer is one of the platforms to transfer the ladder diagram to the PLC. In addition, the HMI can be interfaced with a PLC using NB-Designer software where it provides the best visability with colour touch graphical control panel as shown in Figure 4. The NB-Designer was developed by OMRON to interface it with PLC. When the start button is pressed ON at touch the screen, the PLC will be also ON as well. The pink color button is to move the cylinder A to crush the can. The number of crashes cans will be displayed on the screen. If the bottle stuck in the crusher area, the OFF button will appear and pressing the button will restart the program after removing the can.

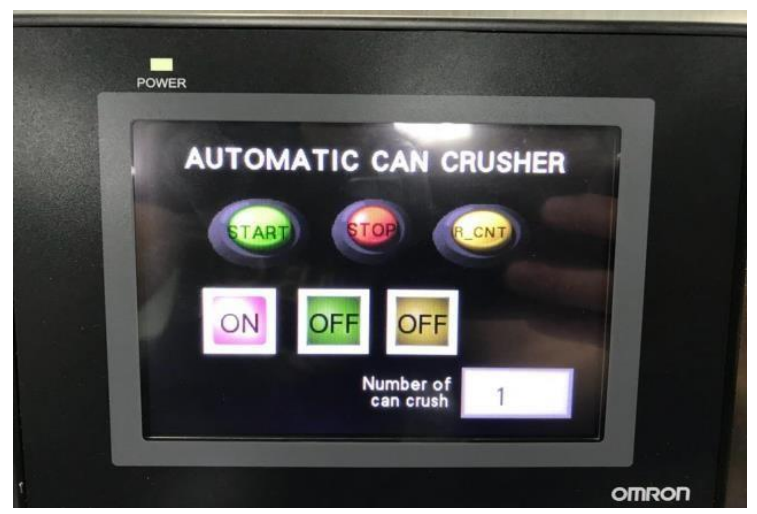

Figure 4. PLC - HMI interface using the NB-Designer software from OMRON shows how the Automatic Can Crusher complete its task with showing how many can it have crush 


\section{RESULTS}

The experiment starts with crushing different type of brand can. As shown in Figure 5, the Nescafe brand is being crushed with different pressure starting from 3 bar until 8 bar. The setting of this bar is mainly due to the valve only able to operate at the pressure of 3 bar. Meaning to say that, below 3 bar it does not turn on. Meanwhile, for the 8 bar is due to the maximum pressure of the test place is 8 bar. That is why the measurement of pressure is being set from 3 till 8. As the pressure increase, the length of the can decreases where it can be clearly seen in the Figures 5-8. Based on the result, the can only able to be crushed when the pressure supply is 6 bar. This means the minimum pressure to crush the can is 6 bar, but it is not completely crushed up to $90 \%$ and above.

The Figure 9 shows the sample of the fail crushed can. This may be due to the position of the can is not good form during the crushing process. As this is the factor that will affect the shape and the percentage of the can being crushed

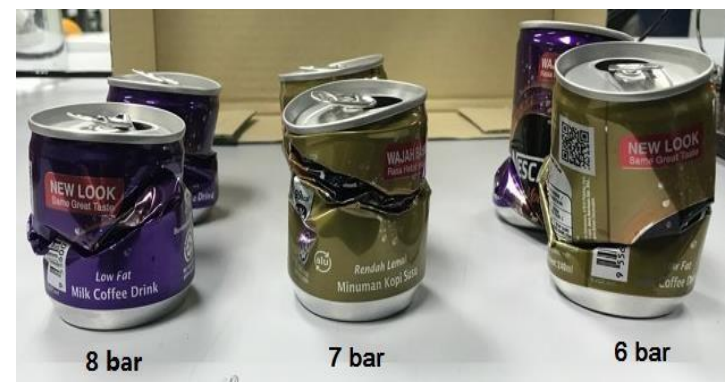

Figure 5. The desired size of Nescafe brand of the cans according to the pressure supply

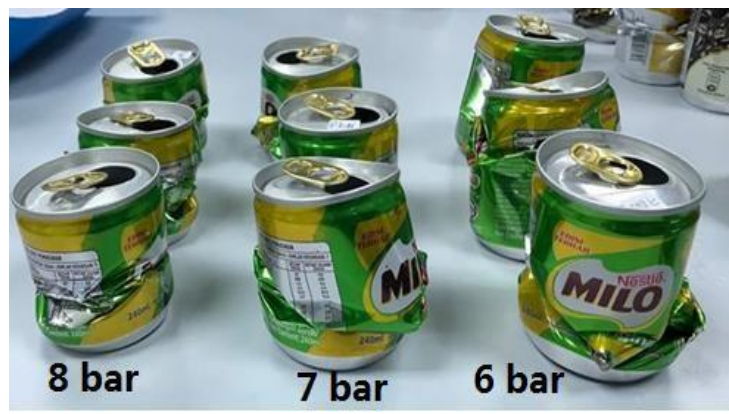

Figure 7. The desired size of the Milo brand of the cans according to the pressure supply

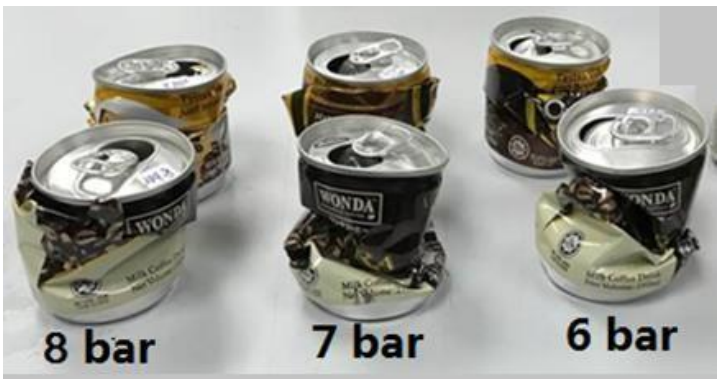

Figure 6. The desired size of Wonda brand of the cans according to the pressure supply

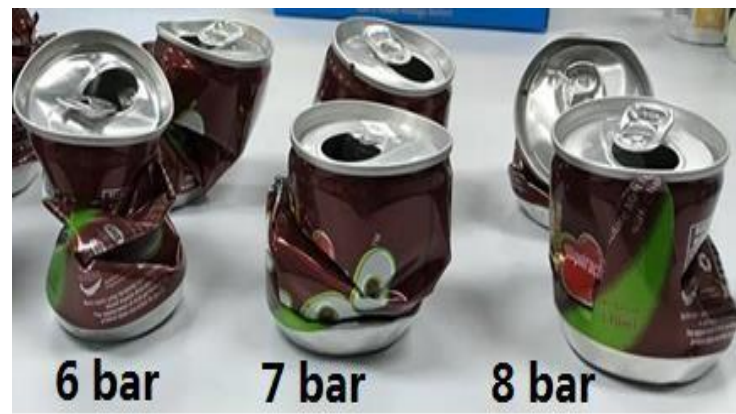

Figure 8. The desired size of Oligo brand of the cans according to the pressure supply

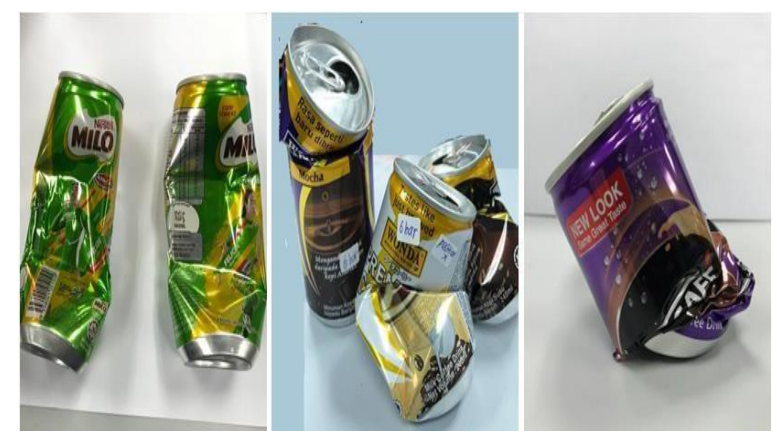

Figure 9. The sample of fail crushed can that could not be crushed perfectly 


\section{DISCUSSION AND ANALYSIS}

\subsection{Analysis on one cycle crushing program}

This analysis is carried out to find out the average length of the can after being crushed with different pressure as shown in Tables 1-4. The data are taken based on 3 trials for each pressure on the same brand. In addition, the percentage of the length of the can after crushing is being calculated as well shown in Figure 10 .

Table 1. Relationship of Pressure against the Length of the NESCAFE's Can

\begin{tabular}{cccccc}
\hline $\begin{array}{c}\text { Pressure } \\
\text { (bar) }\end{array}$ & Trial 1 & $\begin{array}{c}\text { Length }(\mathrm{mm}) \\
\text { Trial 2 }\end{array}$ & Trial 3 & $\begin{array}{c}\text { Average } \\
(\mathrm{mm})\end{array}$ & \% Crushing \\
\hline 6 & 77.72 & 75.84 & 75.21 & 76.26 & 44.57 \\
7 & 62.89 & 61.57 & 58.58 & 58.66 & 55.82 \\
8 & 53.03 & 53.83 & 53.42 & 53.43 & 59.76 \\
\hline
\end{tabular}

Table 2. Relationship of Pressure against the Length of the WONDA's Can

\begin{tabular}{cccccc}
\hline $\begin{array}{c}\text { Pressure } \\
\text { (bar) }\end{array}$ & Trial 1 & $\begin{array}{c}\text { Length }(\mathrm{mm}) \\
\text { Trial 2 }\end{array}$ & Trial 3 & $\begin{array}{c}\text { Average } \\
(\mathrm{mm})\end{array}$ & \% Crushing \\
\hline 6 & 93.86 & 93.15 & 84.99 & 90.67 & 31.76 \\
7 & 62.38 & 59.35 & 62.68 & 61.47 & 53.74 \\
8 & 54.06 & 55.06 & 54.46 & 54.33 & 59.11 \\
\hline
\end{tabular}

Table 3. Relationship of Pressure against the Length of the OLIGO's Can

\begin{tabular}{cccccc}
\hline $\begin{array}{c}\text { Pressure } \\
(\text { bar })\end{array}$ & Trial 1 & $\begin{array}{c}\text { Length }(\mathrm{mm}) \\
\text { Trial 2 }\end{array}$ & Trial 3 & $\begin{array}{c}\text { Average } \\
(\mathrm{mm})\end{array}$ & \% Crushing \\
\hline 6 & 78.54 & 85.31 & 81.92 & 81.92 & 38.19 \\
7 & 64.56 & 67.89 & 68.15 & 66.87 & 49.55 \\
8 & 53.65 & 54.87 & 52.98 & 53.83 & 59.39 \\
\hline
\end{tabular}

Table 4. Relationship of Pressure against the Length of MILO NESTLE's Can

\begin{tabular}{cccccc}
\hline $\begin{array}{c}\text { Pressure } \\
\text { (bar) }\end{array}$ & Trial 1 & $\begin{array}{c}\text { Length }(\mathrm{mm}) \\
\text { Trial 2 }\end{array}$ & Trial 3 & $\begin{array}{c}\text { Average } \\
(\mathrm{mm})\end{array}$ & \% Crushing \\
\hline 6 & 82.56 & 88.68 & 90.18 & 87.14 & 34.04 \\
7 & 62.45 & 61.58 & 64.35 & 62.79 & 52.47 \\
8 & 52.49 & 52.38 & 51.89 & 52.25 & 60.45 \\
\hline
\end{tabular}

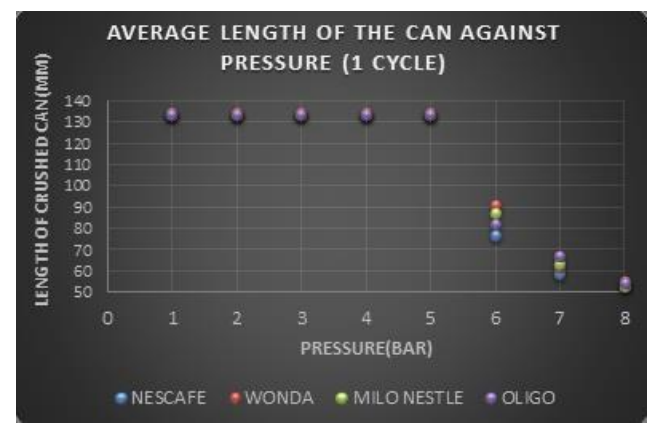

Figure 10. Average length of the can against different pressure

From the data obtained, it shows that the average length of the can is quite linear compares to each other as in the length of the can and the pressure supply. As the pressure increase, the length of the can will decrease. This proves that the pressure supply is inversely proportional to the can after being crushed.

The 12 data for four different brands of the can which apply 6 bar, 7 bar and 8 bar pressure is calculated as shown in Table 5. The findings showed that the coefficient for 8 bar is the lowest that is 0.021 which considered very small and follow by the coefficient of 7 bar pressure that is 0.045 and the coefficient for 6 bar is 0.072 . So, it can be concluded that the coefficient obtained was quite low for each of every bar. 
Meaning to say that, the lower the value of the coefficient of variation in the data, it will be more precise in the estimation.

Table 5. The Coefficient of Variation in the Data

\begin{tabular}{cccc}
\hline Pressure & Mean & Standard Deviation & The coefficient \\
\hline 6 & 81.880 & 5.922 & 0.072 \\
7 & 62.410 & 2.829 & 0.045 \\
8 & 52.560 & 1.105 & 0.021 \\
\hline
\end{tabular}

\subsection{Analyzing on two cycle crushing program}

This analysis is carried out to find out the differences as in the average length of the can compare to the one cycle to check whether it will be affected the length as shown in Tables 6-9. Average length of the can against different pressure as shown in Figure 11.

Table 6. Relationship of Pressure against the Length of the NESCAFE's Can

\begin{tabular}{cccccc}
\hline $\begin{array}{c}\text { Pressure } \\
\text { (bar) }\end{array}$ & Trial 1 & $\begin{array}{c}\text { Length }(\mathrm{mm}) \\
\text { Trial 2 }\end{array}$ & Trial 3 & $\begin{array}{c}\text { Average } \\
(\mathrm{mm})\end{array}$ & \% Crushing \\
\hline 6 & 76.43 & 74.38 & 73.96 & 74.92 & 43.58 \\
7 & 61.43 & 59.65 & 60.57 & 60.55 & 54.40 \\
8 & 52.59 & 52.95 & 52.85 & 52.80 & 60.24 \\
\hline
\end{tabular}

Table 7. Relationship of Pressure against the Length of the WONDA's Can

\begin{tabular}{cccccc}
\hline $\begin{array}{c}\text { Pressure } \\
\text { (bar) }\end{array}$ & Trial 1 & $\begin{array}{c}\text { Length }(\mathrm{mm}) \\
\text { Trial 2 }\end{array}$ & Trial 3 & $\begin{array}{c}\text { Average } \\
(\mathrm{mm})\end{array}$ & \% Crushing \\
\hline 6 & 82.56 & 91.43 & 92.43 & 88.81 & 33.16 \\
7 & 61.14 & 60.13 & 57.45 & 59.57 & 55.17 \\
8 & 53.14 & 51.23 & 54.43 & 52.93 & 60.16 \\
\hline
\end{tabular}

Table 8. Relationship of Pressure against the Length of the OLIGO's Can

\begin{tabular}{cccccc}
\hline $\begin{array}{c}\text { Pressure } \\
(\text { bar) }\end{array}$ & Trial 1 & $\begin{array}{c}\text { Length }(\mathrm{mm}) \\
\text { Trial 2 }\end{array}$ & Trial 3 & $\begin{array}{c}\text { Average } \\
(\mathrm{mm})\end{array}$ & $\%$ Crushing \\
\hline 6 & 83.21 & 78.95 & 80.43 & 80.86 & 38.99 \\
7 & 63.45 & 60.13 & 66.06 & 95.35 & 50.69 \\
8 & 53.14 & 51.23 & 53.81 & 52.67 & 60.26 \\
\hline
\end{tabular}

Table 9. Relationship of Pressure against the Length of the MILO NESTLE's Can

\begin{tabular}{cccccc}
\hline $\begin{array}{c}\text { Pressure } \\
\text { (bar) }\end{array}$ & Trial 1 & $\begin{array}{c}\text { Length }(\mathrm{mm}) \\
\text { Trial 2 }\end{array}$ & Trial 3 & $\begin{array}{c}\text { Average } \\
(\mathrm{mm})\end{array}$ & \% Crushing \\
\hline 6 & 79.65 & 83.46 & 85.65 & 82.92 & 37.23 \\
7 & 63.24 & 63.50 & 65.75 & 64.16 & 51.43 \\
8 & 50.25 & 52.38 & 52.92 & 51.85 & 60.75 \\
\hline
\end{tabular}

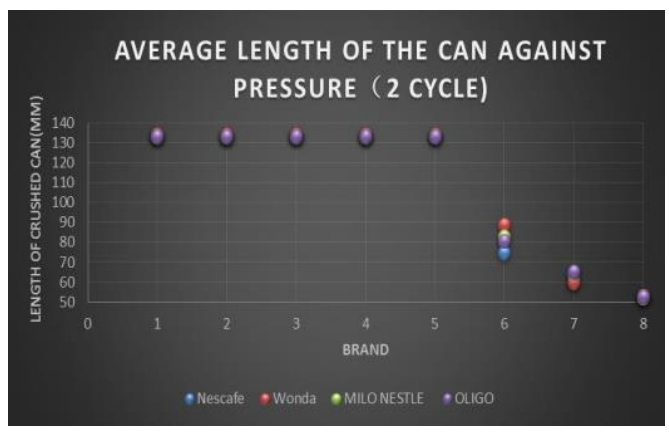

Figure 11. Average length of the can against different pressure

From the data obtained, it shows that the average length of the can as compare to the one cycle. There is no significant difference between the one cycle programmed and two cycles programmed as there is no much difference in the reading of the length of the crushed can for one cycle and two cycles. However, the 
two cycles programmed have advantages over the one cycle as the second times on the compressing of the can is dispersed into the hole provided at the bottom of the machine. This dispersion of the crushed can mechanism is as easy and simple way so that the next can be able to push into the crushing chamber after the first crushed. In short, the second cycle programmed is mainly to ensure the efficiency for the crushing process as well as it helps in dispersing the can automatically into the recycle bin much easier.

The 12 data for four different brands of the can which apply 6 bar, 7 bar and 8 bar pressure is calculated as shown in Table 10. Based on the calculation, the value of the COV for 8 bars is 0.009 which is the lowest. It is obvious that 8 data for 8 bar pressure is the most precise because the value is extremely small as it is not more than 0.01 and followed by the coefficient of 7 bar pressure, which is at 0.046 and the coefficient for 6 bar is 0.077 . So, it can be concluded that the coefficient obtained was quite low for each of every bar. Meaning to say that, the lower the value of the coefficient of variation in the data, it will be more precise in the estimation.

Table 10. The Coefficient of Variation In The Data

\begin{tabular}{cccc} 
& \multicolumn{1}{c}{ Table 10. The Coefficient of Variation In The Data } \\
\hline Pressure & Mean & Standard Deviation & The coefficient \\
\hline 6 & 83.997 & 6.489 & 0.077 \\
7 & 63.040 & 2.898 & 0.046 \\
8 & 107.030 & 1.000 & 0.009 \\
\hline
\end{tabular}

\section{CONCLUSION}

As a conclusion, the automatic can crusher machine is designed and fabricate successfully as a purpose to encourage people to recycle more as can crusher machine is fun and interesting yet maintain an eco-friendly environment. The PLC controlling system works well in the compilation of hardware and software with the pneumatic system as well as the HMI. It can be concluded that 8 bar pressure is the most optimum pressure in crushing the beverage can as the calculated COV is the lowest in 8 bar pressure, yet it can reduce the length of the beverage can to the maximum which is $60 \%$. Besides, it minimizes the crushing force, time and human fatigue with this automatic machine. There are many improvements can be done in future to improve the functionality of the machine to the users. One of the suggestions is by implementing a vendor machine into the can crusher machine where rewards are given to the user when they put the can into the can crusher machine so that it can encourage people to do recycle more. In addition, the machine is suggested to add on with the Internet of Things (IoT) technology whereby the amount of the cans that the users put will be store and the data can be transferred to the network. So, with this data-based purpose provided by IoT, the user can redeem a better reward if they recycle more. Next on will be implementing the sorting system where the machine can differentiate the optical glass, paper instead of differentiating the aluminium and plastic only.

\section{ACKNOWLEDGEMENTS}

This research was sponsored by research grant research was sponsored by research grant RAGS/1/2015/TKO/FTK/03/B00118 under the Centre of Robotics and Industrial Automation (CeRIA), University Teknikal Malaysia Melaka. We would like to thank our colleagues from the Centre for Telecommunication Research \& Innovation (CeTRI), University Teknikal Malaysia Melaka. Thanks to staffs and members of UTeM who give assistance and commitment to me and guide me in various perspectives throughout the project. Special thanks must be given to my friends for ideas and comments regarding to my project.

\section{REFERENCES}

[1] V. N. Kshirsagar, D. S. K. Choudhary and P. A. P. Ninaw, "An Automatic Can or Plastic Bottle Crusher Machine A Review," Int. J. Sci. Res. Dev., vol. 2(2), pp. 66-68, 2014.

[2] M. Fernandes, "A Review on PLC based Automatic Waste Segregator," Int. J. Adv. Res. Comput. Eng. Technol., vol. 5(2), pp. 280-285, 2016.

[3] G. Bharth, S. K. K, S. C. V, and T. H. Lakshiminarayana, "Pneumatic Three Axis Modern Trailer," Natl. Conf. Recent Adv. Mech. Eng., vol. 4(5), pp. 891-901, 2016.

[4] A. Ravi K., B. V. Sundeep, C. Sree V., and N. Mathews, "The Principle of Programmable Logic Controller and its role in Automation," Int. J. Eng. Trends Technol., vol. 4(3), pp. 3, 2013.

[5] A. Patel, A. Wagh, N. Tilekar, S. Thakur, and B. Knowledge, "Cam Follower Can Crusher Vending," Int. J. Res. Eng. Appl. Manag., vol. 2(6), pp. 12-15, 2016. 
[6] D. A. Sawant, M. A. Venkatesh, and R. C. Yeola, "Buckling and Crushing Analysis of Cylindrical Aluminium Cans \& Optimizing the Parameters Effecting Crush Strength Using Fem," Int. Res. J. Eng. Technol., vol. 3(6), pp. 3081-3085, 2016.

\section{BIOGRAPHIES OF AUTHORS}
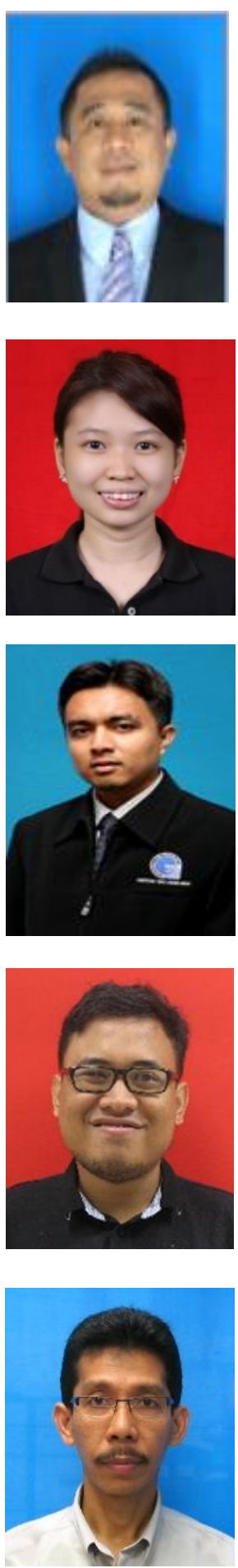

Nik Azran Bin Ab Hadi.Born in the small town of Tanah Merah, Kelantan., His tertiary education began at the MARA Institute of Technology, Shah Alam, where he graduated with a Diploma in Electrical Engineering (Electronic), in 1994. After a short working experience, he left to pursue for his bachelor's degree at the University of Plymouth, Devon England, in 1995. He graduated with a B. Eng (Hons) in Electrical and Electronic Engineering, in July 1997. After graduation, he worked with a few companies. His duties included operating and trouble-shooting geophysical, survey, navigation and bimedical equipments. He received Master of Science Electronic Technology for Sustainable Energy from University of Swansea, Wales, UK. Currently, he works as a Lecturer at Universiti Teknikal Malaysia Melaka (UTeM) and his interests are in power quality and biomedical devices.

Lim Hui Yee is graduated student from Universiti Teknikal Malaysia Melaka. She graduated in Bachelor of Electronic Engineering Technology in Electronic Industry (Hons.) in Universiti Teknikal Malaysia Melaka. Previously. She has been attached the Pre Employement-Internship at Texas Instrument Melaka.

Khalil Azha Mohd Annuar, received his B.Eng degree in Electrical Engineering (Electronic) from Universiti Teknologi Malaysia (UTM), in 2006. He received the M.Eng degree in Mechatronics and Automatic Control engineering also from UTM, in 2014. Currently, he is a Lecturer at Universiti Teknikal Malaysia Melaka (UTeM) and his interests are in control system and artificial intelligent.

Zulhilmi Zaid is a postgraduate student from Universiti Teknikal Malaysia Melaka. Before that, he graduated in Bachelor of Electronic Engineering Technology in Electronic Industries (Hons.) in Universiti Teknikal Malaysia Melaka. Previously, he has been working on a different company, which are OYL Technology Sdn Bhd, as Quality Assurance Engineer and LED Vision Sdn Bhd, as Design Engineer. His area of interest are power electronics, biomedical instrumentation and sensors

Zamre Abd. Ghani received his B.Sc. degree in Electrical Engineering from the University of the Pacific, Stockton, California, USA, M.Eng. degree in Electrical Engineering from Universiti Teknologi Malaysia (UTM), and Ph. D in Electrical, Electronic \& Systems Engineering from Universiti Kebangsaan Malaysia (UKM) in 1987, 2007 and 2014, respectively. Currently he is a Senior Lecturer at the Department of Industrial Electronics, Faculty of Electronic \& Computer Engineering, Universiti Teknikal Malaysia (UTeM) Melaka, Malaysia. His main research interests are power electronics/power converter controllers for photovoltaic applications such as inverters and dc-dc converters. 

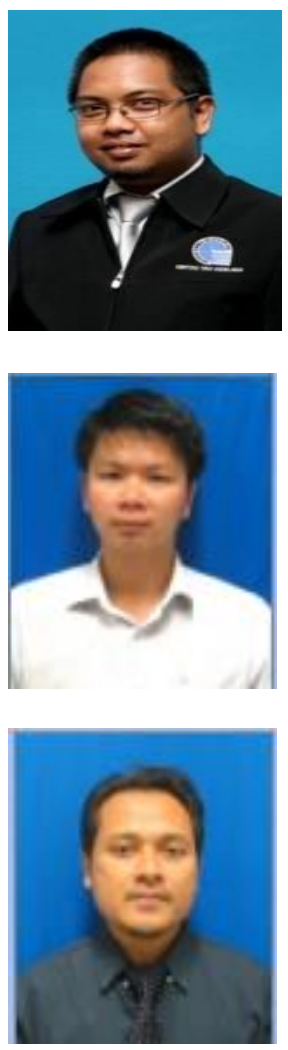

Mohd Firdaus bin Mohd Ab Halim worked in Sony, Intel and Qimonda before joining research institution in 2012. The preference of his research were mainly on energy efficiency, motor control and electrical vehicle. Besides that he led more than 5 research grants and contribute to more as member in 10 research grant. He is now an important member of Faculty of Engineering Technology, UTeM

Amar Faiz Zainal Abidin received his Bachelor of

Engineering in Electrical \& Electronics from University of Nottingham in 2008. While working as Tutor in Universiti Teknologi Malaysia (UTM), he completed his master degrees: Master of Engineering in Electrical (Mechatronics \& Automatic Control) from UTM and Master of Science in Computer Vision from University of Burgundy. Currently, he serves Universiti Teknikal Malaysia Melaka as a Lecturer and his main research interest is in Computational Intelligence.

Mohd Badril Nor Shah received the M. Eng. degree in Mechatronic and Automatic Control, and the Ph.D. degree in Electrical Engineering (Control) from Universiti Teknologi Malaysia, Johor Bahru, Malaysia, in 2011 and 2015, respectively. He also has several years of experience as an Engineer in building and facility maintenance engineering. His research interests include networked control system, real-time control system, robust control, and controller area network (CAN). 